\title{
A New Keto Acid, 5-Acetoxy-4-ketohexanoic Acid, Formed from Ethanol by Yeast
}

\author{
By Takashi Hirabayashi and Tokuya Harada \\ The Institute of Scientific and Industrial Research, Osaka University, \\ Suita-shi, Osaka, Japan \\ Received January 27, 1969
}

\begin{abstract}
Of five strains of yeast tested, three which produced 5-hydroxy-4-ketohexanoic acid (HKH) were also found to form a new keto acid, when grown on medium containing ethanol as the sole carbon source. The new product was isolated in pure form and the structure was investigated by elementary analysis, infrared spectral analysis, NMR analysis and determination of its degradation product.

The compound was shown to be 5-acetoxy-4-ketohexanoic acid. 5-Acetoxy-4-ketohexanoic acid (AKH) was synthesized and found to be identical with the isolated product.
\end{abstract}

In our previous papers, ${ }^{1,21}$ certain strains of yeasts were demonstrated to produce a large amounts of cells and 5-hydroxy-4ketohexanoic acid (HKH) from ethanol.

These strains have also been found to form a new keto acid from ethanol. The present paper describes the production, isolation, chemical properties and structure of this compound and its identification as 5-acetoxy4-ketohexanoic acid.

\section{MATERIALS AND METHODS}

Microorganism. The following organisms were used in this work: Hansenula miso IFO 0146, Pichia mogii IFO 0193, Candida albicans IFO 0583 and Candida tropicalis IFO 0006 (obtained from the Institute of Fermentation, Osaka); Saccharomyces oviformis WH 92 (obtained from the Institute of Suntory Co. Ltd.).

Cultures. The organism was maintained on a glucose (1\%)-Bacto-peptone (1\%) -yeast extract $(0.5 \%)$ agar medium. Volumes of $95 \mathrm{ml}$ of a medium in $500 \mathrm{ml}$ shake-flasks were inoculated with $5 \mathrm{ml}$ of seed culture grown in the same medium. Medium (a)

1) T. Harada and T. Hirabayashi, Agr. Biol. Chem., 32, 1175 (1968).

2) T. Hirabayashi and T. Harada, ibid., 33, 276 (1969). contained $150 \mathrm{mg}$ of $\left(\mathrm{NH}_{4}\right)_{2} \mathrm{HPO}_{4}, 100 \mathrm{mg}$ of $\mathrm{KH}_{2} \mathrm{PO}_{4}$, $50 \mathrm{mg}$ of $\mathrm{MgSO}_{4} \cdot 7 \mathrm{H}_{2} \mathrm{O}, 1 \mathrm{mg}$ each of $\mathrm{NaCl}, \mathrm{MnCl}_{2}$. $4 \mathrm{H}_{2} \mathrm{O}$, and $\mathrm{FeCl}_{3} \cdot 6 \mathrm{H}_{2} \mathrm{O}$ in $100 \mathrm{ml}$ of distilled water and ethanol was added as the sole carbon source at the concentrations given in the results. The medium was adjusted to $\mathrm{pH} 7.2$. Ethanol was filtered through a Seitz-filter and then added to the autoclaved medium. Medium (b) supplements medium (a) with $0.02 \mathrm{~g}$ of yeast extract. Medium (a) was used for culture of Hansenula miso IFO 0146 and Pichia mogii IFO 0193 and medium (b) for culture of Candida albicans IFO 0583, Candida tropicalis IFO 0006 and Saccharomyces oviformis WH92. The culture was shaken reciprocally at 120 strokes permin at an amplitude of $7 \mathrm{~cm}$ at $30^{\circ} \mathrm{C}$.

Paper chromatography. Paper chromatography was carried out by the descending technique on ToyoRoshi No. 52 paper. For development the following solvent systems were used; $n$-butanol: acetic acid: water $(4: 1: 5 \mathrm{v} / \mathrm{v})$ (solvent A); $n$-butanol : pyridine: water $(6: 4: 3 \mathrm{v} / \mathrm{v}$ ) (solvent B). Bromo-cresol-green and ammoniacal silver nitrate reagents were used for detection of acidic and reducing matters, respectively.

Infrared analysis. Infrared analysis of the substances as liquid film was done in an S-type infrared spectrophotometer of Japan Spectroscopic Co. Ltd.

Nuclear magnetic resonance. NMR analysis of the substance as $10 \%$ solution in $\mathrm{CDCl}_{3}$ with tetramethylsilane as the internal standard was done at a sweep 
width of $500 \mathrm{cps}$ at 60 mega cycles.

\section{RESULTS AND DISCUSSION}

\section{Formation of a new keto acid from ethanol}

The organisms were cultured for 6 days adding $4 \%$ ethanol initially and raising the concentration to $6 \%$ after $48 \mathrm{hr}$. When the yeasts (Hansenula miso IFO 0146, Candida albicans IFO 0583 and Saccharomyces oviformis WH 92) were used, $\mathrm{HKH}$ and an unidentified keto acid were detected by paper chromatography in the culture fluid. The $R f$ values of the unidentified keto acid were 0.92 and 0.83 with solvents $\mathrm{A}$ and $\mathrm{B}$, respectively, while those of $\mathrm{HKH}$ were 0.82 and 0.65 , respectively, as shown previously. ${ }^{21}$ The amount (ca. $20 \mathrm{mg} / \mathrm{liter}$ ) of this keto acid formed was rather smaller than that (ca. 200 $\mathrm{mg} /$ liter) of HKH. Strains of yeasts which did not form HKH (Pichia mogii IFO 0193 and Candida tropicalis IFO 0006) did not form this keto acid.

\section{Isolation of the keto acid}

Hansenula miso IFO 0146 was used to isolate the keto acid. After four days incubation of culture medium adding $4 \%$ and $2 \%$ ethanol initially and after $48 \mathrm{hr}$, respectively, the culture fluid was centrifuged at $8000 \mathrm{rpm}$ for $10 \mathrm{~min}$. The supernatant (ca. 4 liters) was evaporated to $1 / 10$ volume in vacuo and adjusted to $\mathrm{pH} 2.0$ with sulphuric acid.

The solution was then continuously extracted with ether for $40 \mathrm{hr}$. The ether extract was evaporated to dryness in vacuo to remove ether. The residue was dissolved in $1 \mathrm{ml}$ of water. The solution was placed on a cellulose column $(3 \times 30 \mathrm{~cm})$ and the material was eluted with the solvent; $n$-butanol : formic acid : water $(19: 1: 10 \mathrm{v} / \mathrm{v})$. Fractions of eluate of $10 \mathrm{ml}$ were collected with a fraction collector. The fractions which contained the material with a motility corresponding to that of the keto acid were evaporated to dryness. The residue was mixed with $1 \mathrm{ml}$ of chloroform and centrifuged. The resulting supernatant was chromatographed on a celite column $(1 \times 40 \mathrm{~cm})$. The column was plugged with cotton and the material was eluted with $100 \mathrm{ml}$ portions of $1,5,10$ and $15 \% n$-butanol in chloroform, both solvents being saturated with water after mixing. Appropriate fractions were collected in a fraction collector and evaporated to dryness (yield $80 \mathrm{mg}$ ). This material is a viscous oil, soluble in water, ethanol, chloroform and ether and insoluble in petroleum ether (bp $30 \sim 60^{\circ} \mathrm{C}$ ).

The keto acid, $[\alpha]_{D}^{20}-18^{\circ}(c=2$, water $)$

Anal. Found: C, 51.01; H, 6.30. Calcd. for $\mathrm{C}_{8} \mathrm{H}_{12} \mathrm{O}_{5}$ : C, 51.06; $\mathrm{H}, 6.38 \%$.

Analysis of the infrared absorption spectrum and the nuclear magnetic resonance spectrum of the keto acid

The infrared absorption spectrum of the keto acid (liquid film) is shown in Fig. 1. The strong absorption band at $1250 \mathrm{~cm}^{-1}$ is typical for a disturbed stretching vibration of an ester group (CO-O-C). The spectrum showed absorption bands at 2990 and 2950 $\mathrm{cm}^{-1}$ for $\mathrm{CH}_{2}$ groups, $\mathrm{CH}$ and $\mathrm{CH}_{3}$ and at $1740 \mathrm{~cm}^{-1}$ for a free acid carbonyl group. The absence of absorption bands near 3400 $\mathrm{cm}^{-1}$ indicates the absence of a hydroxy radical.

The position of the protons on the carbon atoms of the keto acid was ascertained from analysis of NMR spectral data. The spectrum taken using $40 \mathrm{mg}$ of the keto acid in $\mathrm{CDCl}_{3}$ with $2 \%$ tetramethylsilane as standard is shown in Fig. 2. The doublet at $\delta=1.45 \mathrm{ppm}$ indicates that a $-\mathrm{CH}_{3}$ group is adjacent to a $-\mathrm{CH}$ - group. The singlet at $2.18 \mathrm{ppm}$ indicates that there is a $-\mathrm{CH}_{3}$ group adjacent to a $-\mathrm{CO}-$ group. The triplet at $2.8 \mathrm{ppm}$ indicates that a $-\mathrm{CH}_{2} \mathrm{CH}_{2}-$ group is adjacent to carbons without hydrogen atoms. The quartet at $5.2 \mathrm{ppm}$ indicates that a $-\mathrm{CH}-$ group is adjacent to a $-\mathrm{CH}_{3}$ group. There is a broad absorption near $8.0 \mathrm{ppm}$ for the 


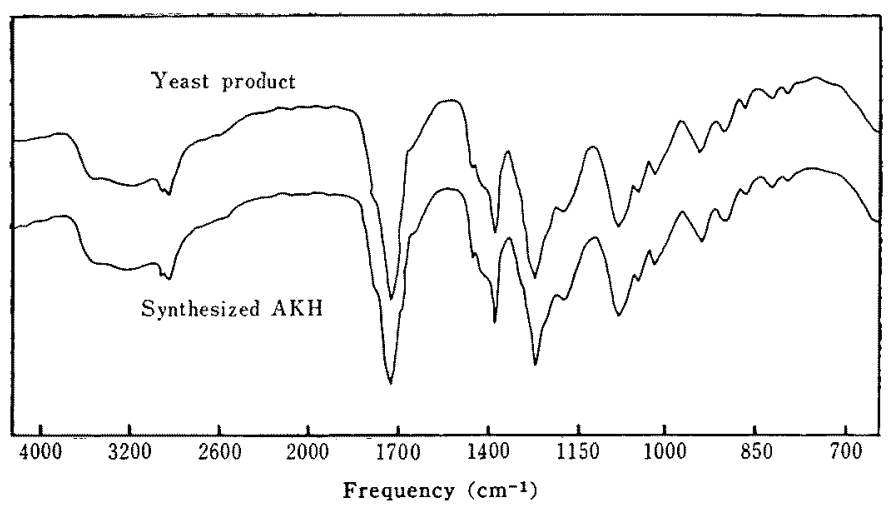

FIG. 1. Infrared Spectra (in liquid film) of the Yeast Product and 5-Acetoxy-4ketohexanoic Acid.

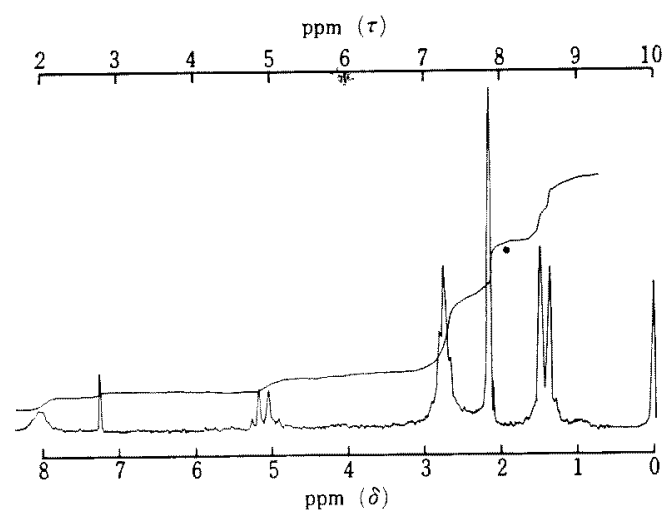

FIG. 2. NMR Spectrum of the Keto Acid Formed from Ethanol.

acidic $H$. The integral ratios are $3: 3: 4: 1: 1$. On the basis of these results, the most reasonable structure of the keto acid is as follows:

\section{$\mathrm{CH}_{3}-\mathrm{CH}\left(\mathrm{CH}_{3} \mathrm{COO}\right)-\mathrm{CO}-\mathrm{CH}_{2}-\mathrm{CH}_{2}-\mathrm{COOH}$ 5-acetoxy-4-ketohexanoic acid}

\section{Decomposition products of the keto acad}

Twenty $\mathrm{mg}$ of the keto acid were dissolved in $0.5 \mathrm{ml}$ of dry methanol and $0.15 \mathrm{ml}$ of a freshly prepared solution of sodium methoxide $(0.05 \mathrm{~g}$ of sodium dissolved in $10 \mathrm{ml}$ of methanol) was added with stirring at a room temperature. When the reaction was complete
(20 $\mathrm{min})$, a test drop of the suspension gave an alkaline reaction with litmus. The sodium was removed by stirring with a slight excess of Amberlite IR-120 ( $\left.\mathrm{H}^{+}\right)$until the solution was neutral and the resin was filtered off. Half of the filtrate was acidified to $\mathrm{pH} 2.0$ with sulphuric acid and steam distilled. The distillate was titrated with $\mathrm{NaOH}$ and concentrated to $1 \mathrm{ml}$. A $p$-bromophenacyl ester derivative which was prepared in the usual way from the concentrated matter and recrystallized from ethanol, showed $\mathrm{mp} 85^{\circ} \mathrm{C}$ (unchanged on addition of the derivative of authentic acetic acid). The distillate contained $41 \mu$ moles of acetic acid, as shown by titration.

The other half of the filtrate was evaporated to a syrup and examined by paper chromatography. A spot developed, which gave an $R f$ value of 0.82 with solvent $\mathrm{A}$ and of 0.65 with solvent $\mathrm{B}$. The $R f$ values were identical with those of $\mathrm{HKH}$. HKH was determined by the method of Bloom et al. ${ }^{31}$ and the filtrate was found to contain $39 \mu$ moles. Positive identification of the acid as $\mathrm{HKH}$ was accomplished by preparing the $p$-phenylphenacyl ester. The crystals obtained melted at $131 \sim 132^{\circ} \mathrm{C}$. There was no depression of

3) R. J. Bloom, P. G. Fuller, J. G. Westerfeld and W. W. Westerfeld, Biochemistry, 5, 3211 (1966). 
the $\mathrm{mp}$ on mixing them with the derivative of authentic $\mathrm{HKH}$ (yeast product). ${ }^{21}$ Degradation studies showed that the keto acid was composed of equimolar quantities of $\mathrm{HKH}$ and acetic acid.

\section{Synthesis of 5-acetoxy-4-ketohexanoic acid}

The 5-hydroxy-4-ketohexanoic acid (100 mg) isolated from the broth was refluxed with acetic anhydride $(6 \mathrm{ml})$ in the presence of sodium acetate $(120 \mathrm{mg})$ for $2.5 \mathrm{hr}$. After cooling, the reaction mixture was poured into ice-cold water $(50 \mathrm{ml})$ and the acetate was extracted with chloroform $(50 \mathrm{ml} \times 3)$. The chloroform layer was washed with water, dried over sodium sulfate and then evaporated to dryness, yielding $85 \mathrm{mg}$ of oil. The crude product was dissolved in chloroform and the solution was passed through a celite column as previously described for the isolated product. Fractions containing $\mathrm{AKH}$ were combined and evaporated to dryness (yield $30 \mathrm{mg}$ ).
This material was arbitrarily assumed to be the purest fraction.

5-Acetoxy-4-ketohexanoic acid $[\alpha]_{\mathrm{D}}^{20}-18^{\circ}(c=$ 2, water)

Anal. Found: C, 51.32; H, 6.53. Calcd. for $\mathrm{C}_{8} \mathrm{H}_{12} \mathrm{O}_{5} ; \mathrm{C}, 51.06 ; \mathrm{H}, 6.38 \%$.

The infrared spectrum of the synthetic $\mathrm{AKH}$ was identical with that of the isolated product, as shown in Fig. 1. NMR spectral analysis also indicated that the product was AKH. The melting point of its $p$-phenylphenacyl ester was $108^{\circ} \mathrm{C}$ and this was not depressed when the material was mixed with the ester of the isolated material. From these results the keto acid was identified as 5acetoxy-4-ketohexanoic acid.

Acknowledgements. The authors wish to thank Dr. T. Hasegawa of the Institute of Fermentation, Osaka and Dr. Y. Oshima of the Institute of Suntory Co. Ltd. for kindly supplying the organisms used in this work. This work was supported by grant from the Waksman Foundation of Japan. 